\title{
İkinci El Otomobil Talep Fiyatının Regresyon Analizi: TR83 Bölgesi Örneği*
}

\begin{abstract}
İkinci El Otomobil Talep Fiyatının Regresyon Analizi: TR83 Bölgesi Örneği

Öz

Yeni ve ikinci el araçlardan oluşan otomotiv piyasası ekonomide önemli bir yere sahiptir. İkinci el otomobil piyasasında fiyatı etkileyen birçok etken vardır. Bu çalışmada otomobil talep fiyatını etkileyen unsurlar ortaya konmuştur. Çalışma TR83 Bölgesi'nde yer alan kent merkezlerini kapsamaktadır. Veriler Şubat-Nisan 2015 döneminde ikinci el araç satışı yapan firmalardan elde edilmiştir. Çalışmada yarı logaritmik regresyon modeli kullanılmıştır. Otomobil markasının Mercedes olması fiyatı artıran en önemli unsur iken, markanın Hyundai olması fiyatı azaltan en önemli unsur olarak bulunmuştur.
\end{abstract}

Anahtar Kelimeler: İkinci El Otomobil Piyasası, Talep Fiyatı, Hedonik Model, Asimetrik Bilgi, TR83 Bölgesi

\author{
Rüştü Yayar ${ }^{1}$
}

Erkan Yılmaz ${ }^{2}$

\begin{abstract}
Regression Analysis of Used Car Demand Price: The Case of TR83 Region
\end{abstract}

\section{Abstract}

The automotive market, which consists of new and used vehicles, has an important place in the economy. There are many factors that affect the price in used car market. In this study, factors affecting the demand price of automobile have been revealed. The study covers urban centers located in the TR83 region. The data was obtained from companies that sold used vehicles during February-April 2015 period. Semi-logarithmic regression model was used in the study. The fact that the car brand is Mercedes is the most important factor that increases the price, while the fact that the brand is Hyundai is the most important factor that reduces the price.

Keywords: Used Car Market, Demand Price, Hedonic Model, Asymmetric Information, TR83 Region

\section{Giriş}

Ulaşım insanlık tarihinin başlangıcından bugüne kadar insan hayatının en önemli ihtiyaçlarından birisi olmuştur. Otomobil, traktör, kamyon gibi araçların henüz insanlığın hizmetine sunulmadığı yakın tarihe kadar ulaşım at, eşek vb. hayvanlar aracılığıyla sağlanmıştır. Bu durum hem zaman hem de ciddi manada bir emek kaybına neden olmuştur.

Zaman içerisinde dünya nüfusunun artması, artan insan ihtiyaçları ve ticaretteki gelişmeler bilim dünyasını ulaşım alanında araştırma yapmak konusunda daha fazla güdülemiştir. Dolayısıyla tekerleğin icadından ilham alan bilim dünyası önce özellikle ticareti temel alarak ticaret yapabileceği ulaşım araçlarını ve tarım araçlarını icat etmiştir. Daha sonra ise elindeki imkânları insanlığın konforuna uygun hale dönüştürme girişimini başlatarak, otomobili insanlığın hizmetine sunmuştur.

Otomotiv sektöründeki gelişmeler ilk yıllarında çok sönük bir seyir izlese de özellikle dünya savaşlarının ağır kayıpları atlatıldıktan sonra hayal edemeyeceği bir ivme kazanmıştır. Otomotiv sektörü günümüzde insanlık tarihinin en yaygın kullanılan araçlarından ve en çok yatırım yapılan

\footnotetext{
* Bu çalışma Gaziosmanpaşa Üniversitesi Sosyal Bilimler Enstitüsü İktisat Anabilim Dalı́nda Doç. Dr. Rüştü Yayar danışmanlığında Erkan Yılmaz tarafından hazırlanan 17 Haziran 2016 tarihinde kabul edilen yüksek lisans tezinin verilerinden yararlanılarak hazırlanmıştır. Gaziosmanpaşa Üniversitesi Bilimsel Araştırma Projeleri birimi tarafından desteklenmiştir. 1 Doç. Dr., Gaziosmanpaşa Üniversitesi, iỉB, İktisat Bölümü, rustu.yayar@gop.edu.tr, http://orcid.org/0000-00016758-4715

${ }^{2}$ Gaziosmanpaşa Üniversitesi, SBE, İktisat Anabilim Dalı, erkanyilmaz6020@gmail.com, http://orcid.org/0000-00017355-3878
} 
iş kollarından biri olmuştur. Başlangıçta sadece ulaşımda bir araç olarak görülen otomobiller, günümüzde lüks ve gösterişli yaşamın sembolü haline gelmiştir.

Önceden sınırlı sayıda üretim ve rekabet olduğundan fiyat tespiti sorun teşkil etmemiştir. Dünya savaşlarından sonra yapılan yatırımlarla gelişen otomotiv sanayisi artık sadece üretmek değil, ürettiği araca fiyat belirleyerek pazar bulma konusunda da düşünür hale gelmiştir. Çünkü çok sayıda firmanın otomobil üretip dünyanın çeşitli yerlerine pazarlaması rekabeti artırmıştır. Otomobiller tüketici tercih ve istekleri doğrultusunda üretilmeye başlanmıştır. Bu durum çok fazla özelliği bir arada bünyesinde barındıran otomobillerin farklı fiyatlarla fiyatlanmasına neden olmuştur. Bugün özellikle TV ve internet sitelerinin reklamlarına bakıldığında sanayi kolları arasında en fazla reklam veren sektörlerden birinin otomotiv sanayisi olduğu görülmektedir. Aynı markada çok farklı özelliklere sahip otomobiller piyasaya sunulmuştur. Her birinin fiyatı farklı olmakla birlikte aynı model aracın birden çok fiyatı bulunmaktadır. 20-30 yıl önce ekonomisini tarım sektörüyle idare eden Türkiye günümüz itibariyle bu idareyi sanayiye bırakmıştır. Sanayide de en önemli piyasa kollarından birini otomotiv sektörü oluşturmaktadır.

Günümüzde otomobiller, çok çeşitli özellik ve donanıma sahiptir. Bunların yanında söz konusu özelliklerin ve donanımın tamir ve temin işleri için diğer önem arz eden konu servis ağı ve yedek parça teminidir. Yeni otomobillerin piyasaya sunulması ikinci el piyasayı da geliştirmektedir. İkinci el otomobil piyasası her geçen gün gelişme göstermektedir. Çok sayıda alıcı ve satıcıyı kapsayan ikinci el otomobil piyasasında denge fiyatının oluşumu incelenmeye değer bir araştırma konusudur. Konu ile ilgili yerli ve yabancı literatürde birçok çalışma bulunmaktadır. Ancak bu çalışmayı yerli çalışmalardan ayıran en önemli husus belirli bir bölgeyi (TR83 Bölgesi) kapsamasıdır. Artan tüketici isteklerine paralel olarak geliştirilen otomobiller ikinci el piyasalarda fiyatlanırken otomobillerin farklı özellikleri fiyatı etkileyebilmektedir. Bu özelliklerin ikinci el otomobil fiyatını belirlemede etkilerinin olduğu, kişi ve kurumlarla yapılan görüşmelerde tespit edilmiştir. Bunların yanı sıra ikinci el otomobilin iç ve dış donanımının, güvenlik önlemlerinin, değişen parçalarının, boya gören parçaların fiyatını belirlemede ne kadar etkiye sahip olup olmadığı araştırılmıştır.

İkinci el araç piyasasında tam rekabet piyasası varsayımlarından olan simetrik bilgi sekteye uğramaktadır. İkinci el araç piyasasında asimetrik bilginin varlığı kötü araçların satılıp, iyi araçların satılmamasıyla sonuçlanır (Akerlof, 1970). Asimetrik bilgiyi asgari düzeye indirebilmek için ikinci el otomobillere ilişkin tüm özellikler dikkate alınmış ve fiyat üzerindeki hedonik etkileri ortaya konulmaya çalışılmıştır. Her geçen gün daha fazla önem kazanan ikinci el araç piyasası için tüketiciyi daha fazla bilgilendirmek, tüketici ve tüketime hazır olan kitleye ikinci el otomobil satarken hangi özelliklere dikkat ederek fiyat belirlenmesi gerektiğini tespit etmek için bu çaıışma yapılmıştır. Çalışma TR83 (Çorum, Amasya, Tokat ve Samsun) bölgesi kent merkezlerini kapsamaktadır.

Konunun önemi, amacı ve kapsamı ilk bölümünde, konuyla ilgili teorik çerçeve ikinci bölümde, çalışmada kullanılan veri ve yöntem üçüncü bölümde, araştırmanın bulgu ve açıklamaları dördüncü bölümde verilmiştir. Son bölümde ise sonuç ve tartışma yer almaktadır.

Çalışmada hem internet sitelerindeki özellikler hem de bizzat firmalarla yapılan görüşmeler sonunda elde edilen bilgilerle ikinci el otomobillerin fiyat belirleyici unsurları ortaya konulmuştur. Tüm bu verileri değerlendirmeye alırken ise hedonik regresyon yönteminden yararlanılmıştır. 


\section{Kavramsal Çerçeve}

Hedonik fiyatlandırma modeli, heterojen malların sahip oldukları özelliklerin her birinin tüketiciye farklı bir tatmin düzeyi sağladığını gösteren, Klasik iktisadın tüketici teorisine dayanmaktadır. Bu yöntem tüketicilerin ödemeye razı olduğu marjinal değerin ve fiyatı etkileyen her bir özelliğin ayrı ayrı belirlenmesine olanak sağlamaktadır (Yayar ve Gül, 2014: 89).

Hedonik fiyat üzerine teorik çalışmalara iki temel yaklaşım büyük ölçüde katkıda bulunmuştur. Birinci yaklaşım, Lancaster (1966) in tüketici teorisinden elde edilmiştir ve ikinci yaklaşım ise Rosen (1974) tarafından öne sürülmüştür. Bu yaklaşımların her ikisi de ürünlerle ilgili özellikleri fiyatlara yüklemeyi amaçlamıştır (Zhang ve Zhang, 2010: 354; Yayar ve Karaca, 2014: 512).

Rosen modelinde, bir mal sınıfı, $\mathrm{n}$ adet özellik ile tanımlanmıştır. Modelde $\mathrm{Z}$ malları göstermektedir. Model aşağıdaki gibi ifade edilmektedir (Rosen, 1974: 34-37; Yayar ve Demir, 2014: 71):

$Z=\left(Z_{1}, Z_{2}, Z_{3}, \cdots, Z_{n}\right)$

Her bir mal, kote olmuş bir piyasaya sahiptir ve aynı zamanda vektör Z'nin sabitlenmiş bir değeriyle ilgilidir bu yüzden ürünlerin piyasası fiyat ve karakteristiklerle ilgili bir fonksiyonu ortaya koymaktadır. Mal talep fonksiyonu aşağıdaki gibi oluşur;

$P(Z)=P\left(Z_{1}, Z_{2}, Z_{3}, \cdots, Z_{n}\right)$

$P$ belirli bir malın piyasa fiyatı, $Z$ ise mal özellikleri vektörüdür. Bu fonksiyon, bir alıcının (satıcının), farklı özelliklere sahip markaların fiyatlarını kıyaslaması ve alışveriş çevresinden elde edilen bir hedonik fiyat regresyon eşitliğidir. Başka bir ifadeyle karakteristiklerin herhangi bir bileşiminin minimum fiyatını verir (Yayar, 2011: 23).

\section{Literatür Özeti}

Literatürde ikinci el otomobil fiyatının belirlenmesine ilişkin yerli ve yabancı birçok çalışma bulunmaktadır. Söz konusu çalışmaların bazıları aşağıda kısaca özetlenmiştir.

Genesova (1993) çalışmasında, toptan ikinci el otomobil piyasasında ters seçimi ampirik olarak incelemiştir. Yeni otomobil bayilerinin (hem yeni hem de ikinci el araba satan) toptan satış pazarında kullanılmış araç ticareti yapma eğiliminde olan satıcılardan (yalnızca kullanılmış arabaları satanlardan) farklı olduğu tespit edilmiştir. Ters seçim modelleri, toptancı piyasasında ticaretin daha yüksek bir oranını satan satıcı tipinin, ortalama olarak, daha yüksek kalitede araba satacağını ve bunun karşılığında daha yüksek bir fiyat alacağını ortaya koymaktadır. Bu tahmini test etmek için bayilerin toptan satış davranışları ve toptan açık artırmada toplanan fiyatlarla ilgili bir anket formundan yararlanılmıştır. Ters seçim için zayıf kanıt bulunmuştur.

Murray ve Sarantis (1999) çalışmalarında İngiltere'de otomobillerin hedonik fiyat modelini tahmin etmek için araba özellikleri hakkında bir dizi panel verisi kullanmışlardır. Çeşitli otomobil modelleri arasındaki fiyat farklılıkları, bireysel otomobil özelliklerindeki farklııklar açısından incelenmiştir. Çalışmada, hedonik fiyat modelinin tahminleri otomobiller için hedonik bir fiyat endeksi oluşturmak için kullanılmıştır.

Pazarlıoğlu ve Güneş (2000) çalışmalarında, Türkiye'deki otomobiller için en uygun hedonik fiyat modelini tahmin etmişlerdir. Illk olarak, Hedonik fiyat modeli teorisi tartışılmış, daha sonra ampirik analiz sonuçları ve en uygun hedonik model belirlenmiştir. Çalışmanın son bölümünde, bulanık hedonik model tahminleri ve normal model tahminleri, müşterileri yüksek düzeyde bilgilendiren en iyi bilgi füzyonunu belirlemek için karşılaştırılmıştır. 
Anderson (2005) İsveç'te yaptığı çalışmada otomobil güvenliği ve marjinal değer güvenliğine odaklanmıştır. Otomobil fiyatları için yarı logaritmik hedonik regresyon modelini kullanmıştır. Çalışmada yıllık yakıt harcamaları, kayıtlı ölümcül olay sayısı, kayıtlı yaralanma sayısı, beygir gücü, bagaj kapasitesi, yakıt türü gibi değişkenler modele katılmıştır. Çalışma sonuçlarına göre, güvenlik düzeyi ile otomobil fiyatı arasında pozitif ilişki bulunmuş, ancak tüketicinin güvenli bir otomobil için yapacağı ödeme istekliliğinin yetersiz olduğu belirlenmiştir.

Alper ve Mumcu (2007) çalışmalarında Türkiye'de yeni otomobil talebini tahmin etmişlerdir. Çalışmada otomobillere ilişkin fiyat, miktar, kalite, menşe ülke ve ürün özelliklerine ilişkin üç aylık veriler ve makroekonomik değişkenlerin üç aylık verileri kullanılmıştır. Dinamik Genelleştirilmiş En Küçük Kareler Tahmini metodu kullanılarak 1996-1999 yılları arasındaki piyasa talebi tahmin edilmiştir. Türkiye'deki otomobil talebi için menşe ülkesinin yanı sıra kalite konusunun da önemli olduğu ve yeni otomobil talebinin kısa vadede fiyat esnekliğinin bulunmadığı bulgularına ulaşılmıştır.

Erdem ve Şentürk (2009) makalelerinde, Türkiye'de ikinci el otomobil fiyatlarını etkileyen faktörleri belirlemek için hedonik regresyon tekniği kullanmışlardır. 1074 ikinci el otomobile ait veri seti kullanılarak, yarı-log, log-doğrusal ve Box-Cox dönüşüm yöntemleri kullanılarak regresyon modelleri tahmin edilmiştir. Sonuçlara göre, dizel motor, otomobilin siyah ve gri renkte olması, otomatik şanzıman, sunroof, üretim yeri (Japonya, Almanya, Kore veya ABD gibi), otomobilin üretim yılı ve motor hacmi gibi özellikler fiyatları olumlu etkilerken, servis sayısının ve İstanbul'daki satış yerinin ikinci el otomobil fiyatlarını olumsuz etkilediği tespit edilmiştir.

Matas ve Raymond'un (2009) İspanya'da 1985-2005 dönemini kapsayan çalışmalarında yarı logaritmik hedonik regresyon modeli kullanılmıştır. Yakıt etkinliği ve büyüklüğün fiyatlar üzerinde olumlu etkiye sahip olduğu belirlenmiştir.

Ecer (2013) çalışmasında ikinci el otomobil fiyatının belirleyicilerini araştırmıştır. Analizlerde iki farklı modelleme yaklaşımı kullanılmıştır. Bunlar; Hedonik model ve Yapay Sinir Ağları (YSA)'dır. Hedonik model kullanılarak öncelikle ikinci el otomobillerin fiyatlarını belirleyen ve istatistiksel olarak anlamlı olan faktörler tespit edilmiştir. Hedonik model sonuçlarına göre ikinci el otomobil fiyatına en çok etki eden faktörler; otomobilin marka ve modeli, motor gücü, kilometresi, yaşı, yakıt türü ve aktarma olmuştur. Hedonik fonksiyonların doğrusal olmama potansiyeline sahip olması sebebiyle çalışmada hedonik modele alternatif olarak YSA kullanılmış ve ikinci el otomobil fiyatları tahmin edilmiştir. Modellerin tahmin performansı sonuçlarına göre YSA, hedonik modele göre daha iyi tahminler gerçekleştirmiş ve üstünlüğü kanıtlanmıştır.

Galarraga vd. (2014) çalışmalarında, otomobilleri göreceli yakıt tüketimi düzeylerine göre sınıflandıran hafif araçlar için Avrupa etiketleme sistemini, enerji verimliliği için yeni bir alternatif gösterge olarak kullanmışlardır. Taşıtlar için fiyat fonksiyonlarını tahmin etmek ve böylece enerji verimliliği açısından yüksek derecelendirilmiş araçların marjinal fiyatını elde etmek için hedonik fiyat metodunu uygulamışlardır. Çalışma sonuçlarına göre, A ve B etiketli araçların benzer özelliklere sahip oldukları, ancak enerji tasarrufu etiketleri düşük olanlardan \%3 ila \%5,9 daha yüksek fiyatlarla satıldıkları belirlenmiştir.

Prieto ve diğerlerinin (2015) yaptığı çalışmada, ikinci el mal piyasalarında beklenti teorisi sonuçları araştırılmaktadır. Özellikle, beklenti teorisi ışı̆̆ında kullanılmış otomobil piyasasının fiyat yapısına hitap eden bir hedonik fiyat modeli geliştirilmiştir. Tüketicilerin, ikinci el otomobilin güvenilirliği beklenen referans değerin altında olduğunda risk alan ve ikinci el otomobilin 
güvenilirliği beklenen referans değerinin üzerindeyken riskten kaçındıkları belirlenmiştir. Model, aynı zamanda, otomobil kalitesinin kalıntı değerleri nasıl etkilediğini ve alıcıların kullanıımış arabaları nasıl değerlendiklerini de göstermektedir.

Daştan (2016) çalışmasında ikinci el otomobil fiyatlarını etkileyen faktörlerin tespitini amaçlamıştır. Bu amaçla, web sitelerinde yer alan ikinci el otomobil ilanlarından elde edilen yatay kesit verileri kullanılmıştır. Nitekim otomobilin özelliklerini yansıtan marka ve model, yaş, çekiş, kilometre, vites, yakıt türü, tork, genişlik, yakıt tankı hacmi, ABS, panoramik cam tavan, arka cam buz çözücü, hidrolik direksiyon, start/stop, sunroof, soğutmalı torpido ve ön görüş kamerası gibi çok sayıda özelliğin otomobil fiyatını etkilediği tespit edilmiştir.

\section{Veri ve Yöntem}

Çalışma kuramsal bölüm ve saha çalışması olmak üzere iki temel çatı altında incelenmiştir. Kuramsal bölüm literatüre dayanmaktadır. Çalışmada alan araştırmasına ilişkin veriler araştırma kapsamında kişi ve kurumlarla yapılan yüz yüze görüşmeler sonucunda şekillenmiştir.

TR83 Bölgesinde bulunan ikinci el oto satış galerileri ve kurumsal şirketlerin ikinci el satış yapan ve bilgi vermeyi kabul eden tüm bayiler ile yüz yüze görüşmeler ile veriler toplanmıştır. Referans dönemi Şubat 2015-Nisan 2015 tarihleri arasıdır. Söz konusu dönem içerisinde satılan ve satışta olan ikinci el otomobiller araştırmanın ana kütlesini oluşturmuştur. Hedonik regresyon modelin oluşturulmasında sıklıkla benimsenen doğrusal, doğrusal logaritmik ve logaritmik doğrusal fonksiyonları denenmiştir. Logaritmik doğrusal modelin en uygun olduğu belirlenmiştir.

\section{Araştırmanın Bulguları ve Sonuçları}

TR83 Bölgesi kentleri olan Samsun, Çorum, Tokat ve Amasya için toplanan verilerin ilk önce iller bazında frekans ve yüzde analizleri yapılmış daha sonra hedonik regresyon modeli tahmin edilmeye çalışılmıştır. Çok çeşitli denemeler sonucunda en uygun fonksiyon tipinin yarı logaritmik olduğuna karar verilmiştir. Bu bölümde ilk olarak araştırma bölgesinde yer alan ikinci el otomobillerin farklı özelliklerine ilişkin frekans ve yüzde analizleri verilmiştir. Daha sonra ise ikinci el otomobil fiyatlarını etkilediği düşünülen değiş̧enlere ilişkin tanımlayıcı istatistikler ve regresyon modeli verilmiştir.

\section{1. İkinci El Otomobillere İlişkin Özellikler}

TR83 Bölgesi'nde analize konu olan ikinci el otomobillerin illere göre dağılımı Tablo 1'de verilmiştir. Tabloya göre araştırma yapılan dönemde Amasya kent merkezinde 120, Tokat kent merkezinde 160, Samsun kent merkezinde 339 ve Çorum kent merkezinde ise 179 ikinci el otomobile ait bilgilerin alındığı görülmektedir. Araştırma döneminde satışı yapılan veya kısa sürede satılması planlanan toplam ikinci el otomobil sayısının 798 olduğu tespit edilmiştir. Araştırma konusu otomobillerin dağılımına yüzde olarak bakıldığında ise tablo 1'de; araştırma bölgesi içinde Amasya kent merkezinin payının \%15,0, Tokat kent merkezinin payının \%20,1, Samsun kent merkezinin payının \%42,5 ve Çorum kent merkezinin payının \%22,4 olduğu görülmektedir. 
Eskişehir Osmangazi Üniversitesi ïBF Dergisi

Tablo 1: Ikinci El Otomobillerin Kent Merkezlerine Göre Dağılımı

\begin{tabular}{lcc}
\hline Kent Merkezleri & Adet & Yüzde \\
\hline Amasya & 120 & 15,0 \\
Tokat & 160 & 20,1 \\
Samsun & 339 & 42,5 \\
Çorum & 179 & 22,4 \\
Toplam & 798 & 100,0 \\
\hline
\end{tabular}

Şubat-Nisan 2015 döneminde elde edilen verilere göre TR83 Bölgesi kent merkezlerinde bulunan satılık ikinci el araçların çeşitli özelliklerine göre dağılımı tablo 2'de sunulmuştur. Araştırma bölgesinde ikinci el otomobillerin markalarına göre dağılımında \%17,5 oranla Renault ilk sırada yer alırken, bunu \%11'le Volkswagen marka takip etmektedir. Araştırma kapsamındaki illerden Çorum'da Toyota, diğerlerinde ise Renault markası ilk sırada yer almaktadır. Bölgede Renault markalı binek otomobil piyasasının gelişmesinde bölgenin coğrafi şartlarının etkili olduğu söylenebilir. Bölgede iller bazında ikinci sırada yer alan marka ise Amasya'da Volkswagen $(\% 11,7)$, Tokat'ta Opel $(\% 11,9)$, Samsun'da Fiat $(\% 12,1)$ ve Çorum'da ise $(\% 12,8)$ Renault'tur. Bu durum bölgedeki otomobillerin servis ağları ve markaların coğrafi dağılımı etkileyebilmektedir.

Araştırmaya konu otomobillerin çeşitli özelliklerine göre analizi aşağıda kısaca özetlenmiştir: Otomobillerin \%33,3'ü beyaz renkli, \%41,4'ü dizel yakıtlı, \%68,9'u manuel vites, \%85,0'inin motor hacmi 1,6 cc ve daha az, \%79,8'i servis imkânına sahip oldukları ve \%9,5'inde panoramik ön cam olduğu tespit edilmiştir.

Tokat'ta en düşük ikinci el otomobil fiyatı 6.250 TL iken, en yüksek fiyat ise 328.500 TL ve ortalama fiyat ise 40.597 TL'dir. Otomobillerden en yaşlısı 31 yaşında iken, ortalama yaş 8,48 yıl olarak bulunmuştur. Yine otomobillerden km'si en düşük olan $1.000 \mathrm{~km}$, en yüksek olan $350.000 \mathrm{~km}$ ve ortalaması $117.624 \mathrm{~km}$ olarak bulunmuştur.

Tablo 2: ikinci El Otomobillerin Özellikleri

\begin{tabular}{|c|c|c|c|c|c|c|c|c|c|c|}
\hline \multirow{2}{*}{ Özellikler } & \multicolumn{2}{|c|}{ Tokat (160) } & \multicolumn{2}{|c|}{ Amasya (120) } & \multicolumn{2}{|c|}{ Çorum (179) } & \multicolumn{2}{|c|}{ Samsun (339) } & \multicolumn{2}{|c|}{ Toplam (798) } \\
\hline & Adet & $\%$ & Adet & $\%$ & Adet & $\%$ & Adet & $\%$ & Adet & $\%$ \\
\hline \multicolumn{11}{|l|}{ Marka } \\
\hline Volkswagen & 17 & 10,6 & 14 & 11,7 & 22 & 12,3 & 35 & 10,3 & 88 & 11,0 \\
\hline Fiat & 8 & 5,0 & 8 & 6,7 & 8 & 4,5 & 41 & 12,1 & 65 & 8,1 \\
\hline Renault & 35 & 21,9 & 32 & 26,7 & 23 & 12,8 & 50 & 14,7 & 140 & 17,5 \\
\hline Ford & 16 & 10,0 & 6 & 5,0 & 13 & 7,3 & 35 & 10,3 & 70 & 8,8 \\
\hline Opel & 19 & 11,9 & 11 & 9,2 & 15 & 8,4 & 20 & 5,9 & 65 & 8,1 \\
\hline Mercedes & 8 & 5,0 & 5 & 4,2 & 11 & 6,1 & 30 & 8,8 & 54 & 6,8 \\
\hline Hyundai & 17 & 10,6 & 1 & ,8 & 13 & 7,3 & 21 & 6,2 & 52 & 6,5 \\
\hline Toyota & 6 & 3,8 & 7 & 5,8 & 30 & 16,8 & 13 & 3,8 & 56 & 7,0 \\
\hline Diğer & 34 & 21,3 & 36 & 30,0 & 44 & 24,6 & 94 & 27,7 & 208 & 26,1 \\
\hline \multicolumn{11}{|l|}{ Renk } \\
\hline Beyaz & 57 & 35,6 & 42 & 35 & 112 & 33 & 55 & 30,7 & 266 & 33,3 \\
\hline Gri & 39 & 24,4 & 29 & 24,2 & 92 & 27,1 & 56 & 31,3 & 216 & 27,1 \\
\hline Siyah & 21 & 13,1 & 16 & 13,3 & 55 & 16,2 & 23 & 12,8 & 115 & 14,4 \\
\hline Diğer & 43 & 26,9 & 33 & 27,5 & 80 & 23,6 & 45 & 25,1 & 201 & 25,2 \\
\hline \multicolumn{11}{|l|}{ Yakıt } \\
\hline Dizel & 58 & 36,3 & 26 & 21,7 & 184 & 54,3 & 62 & 34,6 & 330 & 41,4 \\
\hline Benzin & 35 & 21,9 & 26 & 21,7 & 71 & 20,9 & 55 & 30,7 & 187 & 23,4 \\
\hline LPG & 67 & 41,9 & 68 & 56,7 & 84 & 24,8 & 62 & 34,6 & 281 & 35,2 \\
\hline
\end{tabular}




\begin{tabular}{|c|c|c|c|c|c|c|c|c|c|c|}
\hline \multicolumn{11}{|l|}{ Vites } \\
\hline Manüel & 127 & 79,4 & 87 & 72,5 & 223 & 65,8 & 113 & 63,1 & 550 & 68,9 \\
\hline Yarı oto & 15 & 9,4 & 17 & 14,2 & 59 & 17,4 & 40 & 22,3 & 131 & 16,4 \\
\hline Otomatik & 18 & 11,3 & 16 & 13,3 & 57 & 16,8 & 26 & 14,5 & 117 & 14,7 \\
\hline \multicolumn{11}{|l|}{ Motor } \\
\hline$\leq 1,6 \mathrm{cc}$ & 144 & 90,0 & 100 & 83,3 & 281 & 82,9 & 153 & 85,5 & 678 & 85,0 \\
\hline$>1,6 c c$ & 16 & 10,0 & 20 & 16,7 & 58 & 17,1 & 26 & 14,5 & 120 & 15,0 \\
\hline \multicolumn{11}{|l|}{ Beygir (HP) } \\
\hline $50-75$ & 27 & 16,9 & 28 & 23,3 & 50 & 14,7 & 19 & 10,6 & 124 & 15,5 \\
\hline $76-100$ & 61 & 38,1 & 30 & 25 & 121 & 35,7 & 64 & 35,8 & 276 & 34,6 \\
\hline $101-125$ & 54 & 33,8 & 44 & 36,7 & 107 & 31,6 & 70 & 39,1 & 275 & 34,5 \\
\hline $126+$ & 18 & 11,3 & 18 & 15 & 61 & 18 & 26 & 14,5 & 123 & 15,4 \\
\hline \multicolumn{11}{|l|}{ Servis } \\
\hline Yok & 67 & 41,9 & 69 & 57,5 & 6 & 1,8 & 19 & 10,6 & 161 & 20,2 \\
\hline Var & 93 & 58,1 & 51 & 42,5 & 333 & 98,2 & 160 & 89,4 & 637 & 79,8 \\
\hline \multicolumn{11}{|l|}{ Start/Stop } \\
\hline Yok & 129 & 80,6 & 109 & 90,8 & 290 & 85,5 & 163 & 91,1 & 691 & 86,6 \\
\hline Var & 31 & 19,4 & 11 & 9,2 & 49 & 14,5 & 16 & 8,9 & 107 & 13,4 \\
\hline \multicolumn{11}{|l|}{ Vites } \\
\hline$\leq 5$ & 114 & 71,3 & 92 & 76,7 & 189 & 55,8 & 118 & 65,9 & 513 & 64,3 \\
\hline \multicolumn{11}{|l|}{ Ön kol dayama } \\
\hline Yok & 55 & 34,4 & 57 & 47,5 & 125 & 36,9 & 71 & 39,7 & 308 & 38,6 \\
\hline Var & 105 & 65,6 & 63 & 52,5 & 214 & 63,1 & 108 & 60,3 & 490 & 61,4 \\
\hline \multicolumn{11}{|l|}{ Arka kamera } \\
\hline Yok & 144 & 90,0 & 112 & 93,3 & 299 & 88,2 & 165 & 92,2 & 720 & 90,2 \\
\hline Var & 16 & 10,0 & 8 & 6,7 & 40 & 11,8 & 14 & 7,8 & 78 & 9,8 \\
\hline \multicolumn{11}{|l|}{ LED far } \\
\hline Yok & 117 & 73,1 & 108 & 90,0 & 271 & 79,9 & 168 & 93,9 & 664 & 83,2 \\
\hline Var & 43 & 26,9 & 12 & 10,0 & 68 & 20,1 & 11 & 6,1 & 134 & 16,8 \\
\hline \multicolumn{11}{|l|}{ Panr. ön cam } \\
\hline Yok & 143 & 89,4 & 106 & 88,3 & 305 & 90 & 168 & 93,9 & 722 & 90,5 \\
\hline Var & 17 & 10,6 & 14 & 11,7 & 34 & 10 & 11 & 6,1 & 76 & 9,5 \\
\hline \multicolumn{11}{|l|}{ TV/Nav. } \\
\hline Yok & 115 & 71,9 & 84 & 70,0 & 252 & 74,3 & 106 & 59,2 & 557 & 69,8 \\
\hline Var & 45 & 28,1 & 36 & 30,0 & 87 & 25,7 & 73 & 40,8 & 241 & 30,2 \\
\hline Fiyat & \multicolumn{2}{|c|}{$40.597,81$} & \multicolumn{2}{|c|}{$32.208,33$} & \multicolumn{2}{|c|}{$47.682,30$} & \multicolumn{2}{|c|}{$43.535,75$} & \multicolumn{2}{|c|}{$43.004,82$} \\
\hline Model (yaş) & & 8,48 & & 12,95 & & 7,47 & & 7,91 & & 8,59 \\
\hline Kilometre & 11 & 24,38 & 144 & 98,75 & 117 & 25,96 & & 89,94 & & 56,20 \\
\hline
\end{tabular}

Samsun'daki otomobiller incelediğinde; en düşük otomobil fiyatı $4.500 \mathrm{TL}$, en yüksek otomobil fiyatı $499.000 \mathrm{TL}$ ve ortalama fiyat $47.682 \mathrm{TL}$ 'dir. Otomobillerden en yaşlısı 30, ortalama yaş ise 7,46 olarak bulunmuştur. Otomobillerin km'si en düşük olanı $1.000 \mathrm{~km}$, en yüksek olanı $370.000 \mathrm{~km}$ ve ortalama $\mathrm{km} \mathrm{117,025} \mathrm{km} \mathrm{olarak} \mathrm{bulunmuştur.}$

Amasya'da ikinci el otomobilin ortalama fiyatı 32.208 TL, en ucuz ikinci el otomobil 4.000 TL ve en pahalı otomobil 136.500 TL'dir. İkinci el otomobillerin en eskisi 36 yaşında ve ortalama yaş 12,95 yıl olarak bulunmuştur. Yine araçlar içinde km'si en düşük olan araç $1.100 \mathrm{~km}$, en yüksek olan araç $430.000 \mathrm{~km}$ ve ortalaması $144.698 \mathrm{~km}$ olarak bulunmuştur. Çorum'da ise en düşük ikinci el otomobil fiyatı $3.500 \mathrm{TL}$, en yüksek ikinci el otomobil fiyatı $227.500 \mathrm{TL}$ ve ortalama fiyat 43.535 TL'dir. Yine Çorum'da en yaşlı otomobil 37, ortalama otomobil yaşı ise 7,91 olarak bulunmuştur. Son olarak Çorum'da km'si en düşük olan otomobil $1.000 \mathrm{~km}$, en yüksek olan otomobil 504.000 km ve ortalama araç km'si 117,689 km olarak bulunmuştur.

Araştırma Bölgesi genelinde 798 otomobil içerisinde en düşük fiyat 3.500 TL en yüksek fiyat 499.000 TL ortalama fiyat 43.004 TL'dir. Yine en genç otomobil yaşı 1, en yaşlı otomobil yaşı 37 
ve ortalama otomobil yaşı 8,59 yıl olarak bulunmuştur. Son olarak en düşük kilometreli otomobil 1.000 km, en yüksek kilometreli olan otomobil 504.000 km ve kilometre ortalaması 121.456 $\mathrm{km}$ olarak bulunmuştur.

\section{2. İkinci El Otomobil Talep Fiyatına İlişkin Regresyon Analizi Bulguları}

\subsubsection{Tanımlayıcı İstatistikler}

Analizde kullanılan değişkenlerin tanımlayıcı istatistikleri tablo 3'te analiz sonuçları ise tablo 4'de verilmiştir. Regresyon analizi yalnızca TR83 Bölgesi'nin geneli için yapılmış olması sebebiyle tablo 3' de yer alan değişkenlerin tanımlayıcı istatistikleri bölgenin tamamını kapsamaktadır. Her il için ayrı bir model oluşturulmamıştır. Yukarıda araştırma bölgesinde yer alan ikinci el otomobillerin frekans ve yüzde analizi kısmında ortalamalara ilişkin detaylı açıklamalar yapıldığından burada tekrar üzerinde durulmayacaktır.

Tablo 3: Ikinci El Otomobiller Için Açıklayıcı İstatistikler

\begin{tabular}{|c|c|c|c|c|c|}
\hline Değişkenler & Değişken adı & Ortalama & En Fazla & En Az & $\begin{array}{r}\text { Standart } \\
\text { Sapma }\end{array}$ \\
\hline Aracın logaritmik satılık fiyatı (TL) & LGFYT & 10,40 & 13,12 & 8,16 & 0,73 \\
\hline Aracın bulunduğu il (Tokat=1; değilse $=0$ ) & TKT* $^{*}$ & 0,20 & 1,00 & 0,00 & 0,40 \\
\hline Aracın bulunduğu il (Amasya $=1$; değilse $=0$ ) & AMSY & 0,15 & 1,00 & 0,00 & 0,36 \\
\hline Aracın bulunduğu il (Çorum=1; değilse=0) & ÇRM & 0,22 & 1,00 & 0,00 & 0,42 \\
\hline Aracın bulunduğu il (Samsun=1; değilse=0) & SMSN & 0,42 & 1,00 & 0,00 & 0,49 \\
\hline Aracın markası (Volkswagen $=1$; değilse $=0$ ) & VW & 0,11 & 1,00 & 0,00 & 0,31 \\
\hline Aracın markası (Fiat $=1$; değilse $=0$ ) & FIAT & 0,08 & 1,00 & 0,00 & 0,27 \\
\hline Aracın markası (Toyota $=1$; değilse $=0$ ) & TYT & 0,07 & 1,00 & 0,00 & 0,26 \\
\hline Aracın markası (Mercedes $=1$; değilse $=0$ ) & MRCDS & 0,07 & 1,00 & 0,00 & 0,25 \\
\hline Aracın markası (Hyundai=1; değilse $=0$ ) & HYND & 0,07 & 1,00 & 0,00 & 0,25 \\
\hline Aracın yaşı (yıl) & YAŞ & 8,59 & 37,00 & 1,00 & 7,14 \\
\hline Aracın rengi (gri $=1$; değilse $=0$ ) & GRi & 0,27 & 1,00 & 0,00 & 0,44 \\
\hline Aracın yakıtı (dizel=1; değilse $=0$ ) & DZL & 0,41 & 1,00 & 0,00 & 0,49 \\
\hline Aracın şanzımanı (otomatik=1; yarı otomatik=2; manuel=3) & ŞNZMN & 1,46 & 3,00 & 1,00 & 0,74 \\
\hline Aracın motor hacmi ( $\leq 1600 \mathrm{cc}=1 ;>1600 \mathrm{cc}=2)$ & MTRHCM & 1,15 & 2,00 & 1,00 & 0,36 \\
\hline $\begin{array}{l}\text { Aracın beygir gücü (HP) }(50-75=1 ; 76-100=2 ; 101-125=3 \text {; } \\
126-+=4)\end{array}$ & BYGR & 2,50 & 4,00 & 1,00 & 0,93 \\
\hline Aracın servisi (var $=1 ;$ yok $=0$ & SRVS & 0,80 & 1,00 & 0,00 & 0,40 \\
\hline Aracın hava yastığı (var=1; yok=0) & HVYSTG & 0,85 & 1,00 & 0,00 & 0,36 \\
\hline Aracın lastik arıza göstergesi (var=1; yok=0) & LAG & 0,10 & 1,00 & 0,00 & 0,30 \\
\hline Aracın ısıtmalı koltuk olması (var=1; yok=0) & ISTMLKLTK & 0,16 & 1,00 & 0,00 & 0,37 \\
\hline Aracın start/stop 'unun olması (var=1; yok=0) & STRTSTP & 0,13 & 1,00 & 0,00 & 0,34 \\
\hline Aracın vitesi $(\leq 5=1 ;>5=2)$ & VTS & 1,36 & 2,00 & 1,00 & 0,48 \\
\hline Aracın ön kol dayamasının olması (var=1; yok=0) & KDO & 0,61 & 1,00 & 0,00 & 0,49 \\
\hline Aracın arka kamerasının olması (var=1; yok=0) & ARKKMR & 0,10 & 1,00 & 0,00 & 0,30 \\
\hline Aracın LED farının olması ( var=1; yok=0) & LEDFR & 0,17 & 1,00 & 0,00 & 0,37 \\
\hline Aracın panoramik ön camının olması (var=1; yok=0 & $\mathrm{POC}$ & 0,10 & 1,00 & 0,00 & 0,29 \\
\hline Aracın TV/Navigasyonu olması (var=1; yok=0) & TVNAV & 0,30 & 1,00 & 0,00 & 0,46 \\
\hline
\end{tabular}

\footnotetext{
${ }^{*}$ Temel sınıf olarak alınmıştır.
} 


\subsubsection{Regresyon Analiz Sonuçları}

Regresyon modelinin yapısı, katsayılarının işaretleri ve büyüklükleri uygun olup istatistiksel olarak anlamlı olsalar bile, modelin yorumlanabilir olduğu söylenemez. Modelin geçerliliğinin araştırılması ve geçerli değilse düzeltilmesi gerekir. Bu sebeple tahmin modelinde tahmin hataları arasında bağımlılık olup olmadığı (Autocorrelation), tahmin hatalarının varyanslarının homojen (Heteroscedasticity) olup olmadığı açıklayıcı değişkenler arasında çoklu doğrusal bağlantının (Multicollinearity) olup olmadığı araştırılmıştır (Tarı, 2015).

Tablo 4: Yarı Logaritmik Regresyon Modeli Sonuçları ${ }^{1}$

\begin{tabular}{|c|c|c|c|c|c|}
\hline Değişken & Katsayı & $\begin{array}{r}\text { Standart } \\
\text { Hata } \\
\end{array}$ & $\begin{array}{l}\text { t hesap } \\
\text { Değeri }\end{array}$ & $\begin{array}{l}\text { Olasılık } \\
\text { Değeri }\end{array}$ & $\begin{array}{r}\text { Varyans Artış Fak- } \\
\text { törü }\end{array}$ \\
\hline AMSY & $-0,021710$ & 0,028757 & $-0,754961$ & 0,4505 & 1,660760 \\
\hline ÇRM & 0,064309 & 0,027886 & 2,306151 & 0,0214 & 2,126819 \\
\hline SMSN & 0,005668 & 0,025136 & 0,225483 & 0,8217 & 2,426779 \\
\hline VW & 0,122716 & 0,028609 & 4,289420 & 0,0000 & 1,262291 \\
\hline FIAT & $-0,119419$ & 0,031759 & $-3,760166$ & 0,0002 & 1,186212 \\
\hline TYT & 0,111678 & 0,033435 & 3,340148 & 0,0009 & 1,146590 \\
\hline MRCDS & 0,301618 & 0,038185 & 7,898960 & 0,0000 & 1,445958 \\
\hline HYND & $-0,148579$ & 0,034923 & $-4,254465$ & 0,0000 & 1,167840 \\
\hline YAŞ & $-0,043202$ & 0,018537 & $-2,330582$ & 0,0200 & 3,952820 \\
\hline GRi & $-0,062522$ & 0,002222 & $-28,13433$ & 0,0000 & 1,066268 \\
\hline DZL & 0,089174 & 0,020692 & 4,309643 & 0,0000 & 1,632163 \\
\hline ŞNZMN & 0,053138 & 0,012448 & 4,268801 & 0,0000 & 1,318735 \\
\hline MTRHCM & 0,238085 & 0,032764 & 7,266670 & 0,0000 & 2,155849 \\
\hline BYGR & 0,083641 & 0,013635 & 6,134250 & 0,0000 & 2,539683 \\
\hline SRVS & $-0,056885$ & 0,025991 & $-2,188653$ & 0,0289 & 1,710123 \\
\hline HVYSTG & 0,074558 & 0,036494 & 2,043007 & 0,0414 & 2,692972 \\
\hline LAG & 0,105102 & 0,031898 & 3,294945 & 0,0010 & 1,458627 \\
\hline ISTMLKLTK & 0,183195 & 0,028082 & 6,523673 & 0,0000 & 1,700804 \\
\hline STRTSTP & 0,092102 & 0,028452 & 3,237110 & 0,0013 & 1,477395 \\
\hline VTS & 0,133789 & 0,023368 & 5,725415 & 0,0000 & 1,970618 \\
\hline KDO & 0,063595 & 0,021920 & 2,901247 & 0,0038 & 1,789956 \\
\hline ARKKMR & 0,117840 & 0,034058 & 3,460019 & 0,0006 & 1,607939 \\
\hline LEDFR & 0,100296 & 0,027615 & 3,631936 & 0,0003 & 1,674860 \\
\hline POC & 0,091663 & 0,030641 & 2,991474 & 0,0029 & 1,271690 \\
\hline TVNAV & 0,051951 & 0,020800 & 2,497627 & 0,0127 & 1,433581 \\
\hline $\mathrm{C}$ & 9,972500 & 0,064218 & 155,2922 & 0,0000 & 1,660760 \\
\hline $\bar{N}$ & & 798 & & & \\
\hline $\mathrm{R}^{2}$ & & 0,906677 & Düzetilmiş $\mathrm{R}^{2}$ & & 0,903655 \\
\hline F-istatistiği & & 300,0133 & Prob. (F-istatistiği) & & 0,000000 \\
\hline \multicolumn{2}{|c|}{ Breusch-Godfrey LM Testi } & 2,766908 & Prob. Ki-kare (2) & & 0,250700 \\
\hline \multicolumn{2}{|c|}{ White testi (Değişen varyans) } & 310,0503 & Prob. Ki-kare (302) & & 0,362500 \\
\hline
\end{tabular}

${ }^{1}$ Modelin yarı logaritmik olması sebebiyle kukla değişkenin bağımlı değişken üzerindeki nispi etkisi Halvorsen ve Palmquist yaklaşımı $\left[100\left(e^{\beta}-1\right)\right]$ ile hesaplanmıştır.

Çoklu regresyon analizinde hata teriminin birbirini izleyen değerleri arasında ilişki bulunmasına otokorelasyon denir. Bu durum, genel doğrusal regresyon modelinin önemli bir varsayımından sapmadır. Genel doğrusal regresyon modeli varsayım gereği olarak, hata terimleri arasında bir ilişki yoktur. Ekonometrik modelde otokorelasyon probleminin varlığı durumunda, anlamsız bir katsayının anlamlı olma olasılığı artar, $R^{2}$ yükselir. Bu yüzden $F$ değeri olduğundan büyük bulunur. Sonuç olarak $\mathrm{t}$ ve $\mathrm{F}$ testleri güvenilirliğini yitirip yanıltıcı sonuç verirler. İkinci el otomobil fiyatlarının tespitine ilişkin elde edilen modelde otokorelasyon problemi Breusch- 
Godfrey otokorelasyon LM Testi ile araştırılmış ve böyle bir problemin olmadığı sonucuna varılmıştır.

Değişen varyans hata teriminin varyansının tüm gözlemler için aynı olmaması anlamına gelir. Bağımsız değişken değerlerine bağlı olarak bağımlı değişkenin koşullu varyansı, bağımsız değişken hangi değerleri alırsa alsın değişmemelidir. Ortalama değişse bile ortalama etrafındaki dağılım değişmemelidir. Aksi halde değişen varyans durumundan söz edilir. Değişen varyans olması durumunda parametre tahmincilerinin varyanslarının da olduğundan büyük çıkmasına ve bu da t testi sonucunun olduğundan küçük olmasına neden olur. Böyle bir durumda da bir katsayının anlamsız olarak yorumlanması olasılığı söz konusudur. Bu çalışmanın tahmin modelinde değişen varyansın olup olmadığı White testi ile araştırılmış ve böyle bir problemin olmadığı belirlenmiştir.

Regresyon denklemlerinde kullanılan açıklayıcı değişkenler arasında bazen doğruya yakın bir ilişki vardır. Yani bu değişkenler arasında korelasyon katsayısı birdir. Böyle bir durumda parametreleri hesaplamak mümkün olmaz. Standart hata çok büyür. Bir ve birden fazla katsayının $t$ değeri istatistiki olarak anlamsız olur. Tahmin modelinde çoklu doğrusallık varyans artırıcı faktör (VIF) yardımıyla araştırılmıştır. Genel kabul gören kurala göre eğer VIF değerleri 10 'un altında ise değişkenler arasında önemli bir doğrusallık sorunu olmadığı kabul edilir. Diğer taraftan eğer VIF değerleri 5 'in altında ise hiç sorun olmadığı, 10' un üzerinde ise ciddi bir doğrusallık problemi olduğu anlamına gelir (Greene, 2003; Asteriou, 2006). Tablo 4'e göre VIF değerleri 10'un hatta 5 'in altında olması nedeniyle regresyon modelinde çoklu doğrusallık sorununun olmadığı çok net bir şekilde anlaşılmaktadır.

Tablo 4'de yarı logaritmik regresyon modeli ile ikinci el bir otomobilin fiyatını düşürücü ve arttırıcı unsurları verilmiştir. Buna göre ikinci el bir otomobilin fiyatını belirleyen unsurlar ve oranları şu şekildedir:

Belirlilik katsayısı $\left(\mathrm{R}^{2}\right)$ bağımsız değişkenlerin bağımlı değişkeni ne kadar açıkladığını ifade eder. Belirlilik katsayısı 0,90 bulunmuş olup, bunun anlamı modelde yer alan bağımsız değişkenler, bağımlı değişkeni \%90 oranında açıklamaktadır. Modele katılan değişkenlerin bütün olarak anlamlı olup olmadığını ifade eden F Testi; 300,0133 olup olasılık değeri \%5 den küçüktür. Bu sonuç oluşturulan modelin bütün olarak anlamlı olduğunu ifade etmektedir. Modele ilişkin değişkenlerin katsayıları ve yüzde etkileri tablo 5'de ayrıntılı olarak verilmiştir.

Yarı logaritmik bir fonksiyonda regresyon katsayısı bağımsız değişkendeki bir birimlik değişmeye karşılık bağımlı değişkendeki göreli değişmeyi göstermektedir. Göreli değişme 100 ile çarpılırsa yüzde değişme bulunur. Ancak bu açıklama değişkenin yalnızca sürekli bir değişken olması durumunda geçerlidir. Kukla değişkenin bağımlı değişkendeki göreli etkisini bulmak için, tahmin edilen regresyon katsayısının e tabanına göre ters logaritması alınır ve bulunan değerden 1 rakamı çıkarılır.

Tablo 5'e göre ikinci el otomobilin Çorum kent merkezinde yer almasının Tokat'a göre fiyatını \%6,64 artırdığı söylenebilir. İkinci el otomobilin Amasya'da ve Samsun'da olması değişkenlerinin olasılık değerleri \%5'den büyük çıkmış ve dolayısıyla anlamlı bulunmamıştır. İkinci el otomobil fiyatının belirlenmesinde marka önemli bir göstergedir. Analiz sonuçlarına göre ikinci el otomobilin markasının Volkswagen olmasının \%13,06 Toyota olmasının \%11,82 ve Mercedes olmasının ise \%35,20 oranda talep fiyatını artırıcı etki yaptığı tespit edilmiştir. Çalışma sonucuna göre bilinen markaların fiyatı artırıcı yönde etkilemesi literatürle uyumlu bulunmuştur. 
İkinci el otomobilin bir yıl yaşlanması otomobil talep fiyatını \%4,32 oranında düşürmektedir. Otomobil renginin gri olması fiyatını \%6,06 oranında düşürürken, yakıtının dizel olması ise ikinci el otomobilin fiyatını \%9,33 oranında artırmaktadır. Şanzımanın otomatik olması otomobilin talep fiyatını $\% 5,46$, motor hacminin $1600 \mathrm{cc}$ den büyük olması $\% 26,88$ ve beygir gücündeki bir birimlik artış \%8,72 oranında artırmaktadır. Servise sahip olma talep fiyatını \%5,53 oranında düşürmektedir. Bunun sebebi olarak ise araştırma yapılan Şubat-Nisan 2015 döneminde karşılaşılan araçların çok büyük bir bölümünün ekonomik olarak daha hesaplı olan marka ve modellerden oluştuğu ve bu markaların servise sahip olduğu bulunmuştur. Ancak daha üst sınıfa hitap eden ve fiyat olarak yüksek olan marka ve modellerin servisleri hemen hemen hiç bulunmamaktadır. Bu sonuçla servis özelliği fiyatı düşürücü bir unsur olarak bulunmuştur.

Tablo 5: Regresyon Katsayıları Yüzde Etkileri

\begin{tabular}{|c|c|c|}
\hline Değişken & Katsayı & Yüzde Etki \\
\hline AMSY & $-0,021710$ & $-2,15$ \\
\hline ÇRM & 0,064309 & 6,64 \\
\hline SMSN & 0,005668 & 0,57 \\
\hline VW & 0,122716 & 13,06 \\
\hline FIAT & $-0,119419$ & $-11,26$ \\
\hline TYT & 0,111678 & 11,82 \\
\hline MRCDS & 0,301618 & 35,20 \\
\hline HYND & $-0,148579$ & $-13,81$ \\
\hline YAŞ & $-0,043202$ & $-4,32$ \\
\hline GRi & $-0,062522$ & $-6,06$ \\
\hline DZL & 0,089174 & 9,33 \\
\hline ŞNZMN & 0,053138 & 5,46 \\
\hline MTRHCM & 0,238085 & 26,88 \\
\hline BYGR & 0,083641 & 8,72 \\
\hline SRVS & $-0,056885$ & $-5,53$ \\
\hline HVYSTG & 0,074558 & 7,74 \\
\hline LAG & 0,105102 & 11,08 \\
\hline ISTMLKLTK & 0,183195 & 20,10 \\
\hline STRTSTP & 0,092102 & 9,65 \\
\hline VTS & 0,133789 & 14,32 \\
\hline KDO & 0,063595 & 6,57 \\
\hline ARKKMR & 0,117840 & 12,51 \\
\hline LEDFR & 0,100296 & 10,55 \\
\hline POC & 0,091663 & 9,60 \\
\hline TVNAV & 0,051951 & 5,33 \\
\hline
\end{tabular}

Not: Koyu yazılmış değişkenler istatistiki olarak anlamlı bulunmuştur.

Hava yastığı, lastik arıza göstergesi, ısıtmalı koltuk, start/stop, vitesin 5'den fazla olması, ön kol dayama, arka kamera, LED far, panoramik ön cam, TV/navigasyon gibi özelliklerin olması fiyatı artırıcı unsurlar olarak bulunmuştur.

Ecer (2013), internetteki satış siteleri üzerinden aldığı verilerle yapmış olduğu araştırmasında, otomobil fiyatına en çok etki eden faktörleri aracın markası, modeli, motor gücü, kilometresi, yaşı, yakıt türü ve aktarma olarak bulmuştur. Bu çalışmada ise yukarıda sayılan faktörlere ek olarak, motor hacmi, Isıtmalı koltuk, arka kamera, vites sayısı, start/stop ve panoramik ön cam gibi faktörler de etkili bulunmuştur (Ecer, 2013). 


\section{Sonuç, Tartışma ve Öneriler}

Otomotiv sanayii dünyada yaklaşık 150 yıldır, Türkiye'de ise 50 yıldan bugüne büyük gelişme kaydetmiştir. Özellikle 21.yy'da talebin artması ile büyüyen piyasalar, dünyanın her bölgesinde kolaylaşan ulaşım, sanayi ürünlerinin etkin bir biçimde yayılmasını sağlamıştır. Artan kredi destekleri, eski yıllara göre düşük faiz oranları, devletin engelli, gazi, şehit yakınlarına sağladığı satın alma olanakları, otomotiv şirketlerinin indirim kampanyaları gibi etkenler Türkiye'de sıfır otomotiv kullanımının artmasını sağlayan önemli faktörler arasında gösterilebilir. Sıfır km araç alımındaki bu kolaylıklarla birlikte, artan sıfır araç satışları ikinci el otomotiv piyasasının da büyümesini sağlamaktadır. Sıfır araç satın alımlarını kolaylaştıııc etkenlerin yanı sıra araçlara eklenen yeni donanım ve özelikler kullanıcıları aracını daha kısa sürede yenilemeye teşvik etmektedir. Bu çalışmada TR83 Bölgesi'nde ikinci el olarak satılan otomobillerin talep fiyatını etkileyen temel unsurların tespit edilmesi amaçlanmıştır.

TR83 bölgesinde araştırma yapılan dönemde ikinci el otomobillerin ortalama fiyatları kent merkezleri açısından incelendiğinde, en düşük fiyat 32.208 TL ile Amasya, en yüksek fiyat ise 47.682 TL ile Samsun'dadır. TR83 Bölgesinde yer alan dört il içinde gelişme ve gelir seviyesi en yüksek il olan Samsun'un en yüksek fiyat ortalamasına sahip olması beklenen bir sonuçtur. Yine dört kent merkezi içinde kalkınma ve gelir seviyesi bakımından en düşük il olan Amasya'nın en düşük fiyat ortalamasına sahip olması da beklenen bir sonuçtur. Otomobiller yaş ortalaması açısından incelendiğinde; fiyat ortalamalarında olduğu gibi kent merkezlerinden kalkınma seviyesi yüksek olan Samsun'da araçların daha yüksek modelde olduğu, yani daha genç olduğu görülmüştür. Kalkınma seviyesi düştükçe, araç modellerinin düştüğü yani yaşlarının artığı görülmüştür.

Araştırma sonuçlarına göre ikinci el otomobil talep fiyatını etkileyen fiyat artırıcı özellikler; aracın Çorum kent merkezinde yer alması, markasının Volkswagen, Toyota, Mercedes olması, dizel yakıt kullanması, lastik arıza göstergesine sahip olması, motor silindir hacminin büyük olması, start/stop özelliğinin olması, arka kameraya sahip olması şeklinde tespit edilmiştir. İkinci el otomobil talep fiyatını düşürücü özellikler ise; otomobil modelinin eski olması, renginin gri olması ve servis imkânına sahip olmasıdır.

Bu araştırmada ikinci el otomobil talep fiyatının belirleyicileri satıcı açısından analiz edilmiştir. Bulunan sonuçların iktisat ve işletme bölümündeki araştırmacılar başta olmak üzere, ikinci el aracına fiyat belirlemek isteyen kullanıcılara fayda sağlayacağı beklenmektedir. Bundan sonra bu konuyla ilgili çalışma yapmak isteyen araştırıcıların daha geniş bir popülasyonu ve firmalarla birlikte tüketicileri de dikkate almaları ve farklı modeller geliştirmeleri literatüre katkıyı artırabilecektir. 


\section{Kaynaklar}

Akerlof, George A. (1970), "The Market for Lemons: Quality Uncertainty and the Market Mechanism", The Journal of Economic, 84(August), 488-500.

Alper, C. Emre \& Ayşe Mumcu (2007), "Interaction between Price, Quality and Country of Origin When Estimating Automobile Demand: The Case of Turkey", Applied Economics, 39, 1789-1796.

Andersson, Henrik (2005), "The Value of Safety as Revealed in the Swedish Car Market: An Application of the Hedonic Pricing Approach", Journal of Risk and Uncertainty, 30(3), 211-239.

Asteriou, Dimitrios (2006), Applied Econometrics: A Modern Approach Using EViews and Microfit, Palgrave Macmillan, New York.

Daştan, Hüseyin (2016), "Türkiye'de İkinci El Otomobil Fiyatlarını Etkileyen Faktörlerin Hedonik Fiyat Modeli İle Belirlenmesi", Gazi Üniversitesi Iktisadi ve Idari Bilimler Fakültesi Dergisi, 18(1), 303-327.

Ecer, Fatih (2013), "Türkiye'de 2. El Otomobil Fiyatının Tahmini ve Fiyat Belirleyicilerinin Tahmini”, Anadolu Üniversitesi Sosyal Bilimler Dergisi, 13(4), 101-112.

Erdem, Cumhur ve İsmail Şentürk (2009), “A Hedonic Analysis of Used Car Prices in Turkey", International Journal of Economic Perspectives, 3(2), 141-149.

Galarraga, Ibon, Ana Ramos, Josu Lucas \& Xavier Labandeira (2014), "The Price of Energy Efficiency in the Spanish Car Market", Transport Policy, 36 (2014), 272-282.

Genesove, David (1993), "Adverse Selection in the Wholesale Used Car Market”, Journal of Political Economy, 101(4), 644-665.

Greene, William H. (2003), Econometric Analysis, 5th edition, Prentice-Hall, New Jersey.

Halvorsen, Robert \& Raymond Palmquist (1980), "The Interpretation of Dummy Variables in Semi Logarithmic Equations", American Economic Review, 70, 474-475.

Lancester, Kelvin J. (1966), “A New Approach to Consumer Theory”, Journal of Political Economy, 74(2), $132-157$.

Matas, Anna \& Josep-Lluis Raymond (2009), "Hedonic Prices for Cars: An Application to the Spanish Car Market, 19812005", Applied Economics, 41, 2887-2904.

Murray, Jonathan \& Nicholas Sarantis (1999), “Price-Quality Relations and Hedonic Price Indexes for Cars in the United Kingdom", International Journal of the Economics of Business, 6(1), 5-27.

Pazarlıoğlu, M. Vedat ve Mustafa Güneş (2000), "The Hedonic Price Model for Fusion on Car Market", International Conference of of Information Fusion, Paris, France, 4-13, http://ieeexplore.ieee.org/document/862707/, (Erişim: 20.08.2016).

Prieto, Marc, Barbara Caemmerer \& George Baltas (2015), “Using a Hedonic Price Model to Test Prospect Theory Assertions: The Asymmetrical and Nonlinear Effect of Reliability on Used Car Prices", Journal of Retailing and Consumer Services, 22 (2015), 206-212.

Rosen, Sherwin (1974), "Hedonic Prices and Implicit Markets: Product Differentiation in Pure Competition”, Journal of Political Economy, 8(1), 34-55.

Tarı, Recep (2015), Ekonometri, Kocaeli: Umuttepe Yayınları.

Yayar, Rüştü (2011), “Dizüstü Bilgisayar Piyasasında Hedonik Talep Parametrelerinin Tahminlenmesi”, KMÜ Sosyal ve Ekonomik Araştırmalar Dergisi, 13(21), 21-27.

Yayar, Rüştü ve Deniz Gül (2014), “Mersin Kent Merkezinde Konut Piyasası Fiyatlarının Hedonik Tahmini”, Anadolu Üniversitesi Sosyal Bilimler Dergisi, 14(3), 87-100.

Yayar, Rüştü ve S. Serdar Karaca (2014), “Konut Fiyatlarına Etki Eden Faktörlerin Hedonik Modelle Belirlenmesi: TR83 Bölgesi Örneği”, Ege Akademik Bakış Dergisi, 14(4), 509-518.

Yayar, Rüştü ve Derya Demir (2014), “Hedonic Estimation of Housing Market Prices in Turkey”, Erciyes Üniversitesi iïBF Dergisi, 43, 67-82.

Zhang, Hongjing \& Mucong Zhang (2010), "Environment Hedonic Price Analysis: Evidence from Jilin City", Second International Conference on Communication Systems, Networks and Applications, 354-357, 29 June-1 July 2010, Hong Kong, China. 
Eskişehir Osmangazi Üniversitesi IïBF Dergisi 